\title{
Cidade, urbanismo e mobilidade urbana
}

Elson Manoel Pereira*

\section{Resumo}

A mobilidade é um atributo do território e um direito do cidadão urbano. Para a solução de seus problemas faz-se necessário a compreensão da cidade, como elemento complexo. As soluções de mobilidade precisam superar a visão puramente técnica e abordá-la como uma realidade constitutiva da sociedade e da cidade contemporâneas.

Palavras-chave: Mobilidade urbana; Direito à cidade; Transporte urbano.

City, urban planning and mobility

\section{Abstract}

Mobility is an attribute of the territory. To search for good solutions for mobility-related problems it is necessary to understand the city as a complex element. Mobility solutions need to overcome the purely technical vision and approach to mobility as a constitutive reality of society and the contemporary city.

Keys words: Urban mobility; Right to the city; Urban transport.

Professor do departamento de Geociências e dos Programas de PósGraduação em Geografia e de Pós-Graduação em Urbanismo, História e Arquitetura da Cidade - UFSC (elsonmp@hotmail.com).

Geosul, Florianópolis, v. 29, ESPECIAL, p 73-92, jul./dez. 2014 
PEREIRA, E.M. Cidade, urbanismo e mobilidade urbana.

\section{Introdução}

Um dos temas recorrentes no debate sobre a cidade brasileira hoje é a dificuldade de se deslocar no interior de seu território. A Mobilidade Urbana está na moda; ela está no debate acadêmico, no debate político, nos programas de televisão, mas principalmente afetando o cotidiano das pessoas que vivem em nossas cidades. Mas, apesar de estar em pauta, há muita imprecisão em relação ao seu entendimento; há muita opinião sem base científica e acima de tudo, há um empobrecimento do debate sobre a mobilidade, pois muitas vezes ele é restrito ao aspecto técnico dos meios de transporte.

É preciso compreender a necessidade de mobilidade como uma característica fundamental da sociedade e cidade contemporâneas; desta forma, é necessário igualmente compreendêla a partir de sua articulação com as demais políticas urbanas.

\section{Uma distinção fundamental}

Preliminarmente é preciso, para avançarmos na compreensão do tema, que façamos uma diferenciação entre os conceitos de mobilidade e de transporte: transporte é o movimento de pessoas ou mercadorias com utilização de meios de transporte individual ou coletivo; mobilidade urbana é um atributo do território que diz respeito ao acesso fácil a diferentes áreas de uma cidade; deve ser entendida de uma forma ampla, articulada com a própria forma da cidade, como o resultado de um conjunto de políticas de transporte, de circulação, de acessibilidade e de trânsito, além das demais políticas urbanas; o objetivo maior de uma política de mobilidade urbana seria o de priorizar o cidadão na efetivação de seus anseios e necessidades, melhorando as condições gerais de deslocamento na cidade.

A indiferenciação dos termos transporte e mobilidade reduz as possibilidades de soluções para os problemas relacionados a esta última. Em Florianópolis, por exemplo, há dez anos, quando se 
PEREIRA, E.M. Cidade, urbanismo e mobilidade urbana.

falava em problemas de mobilidade urbana logo se apontava como solução a construção de uma nova ponte, elemento fundamental do sistema viário da cidade e, portanto essencial num sistema de transporte rodoviário.

O debate público ajudou a mostrar que os problemas de mobilidade não diziam apenas ao sistema viário e seu principal gargalo em Florianópolis: a ponte. Outros elementos, como o fato da cidade ter uma mobilidade baseada no transporte predominantemente rodoviário individual (automóvel), a insuficiência de transporte público, a dificuldade de intermodalidade e a própria ocupação dispersa e ao mesmo tempo concentrada em alguns pontos do território, foram apontados, no debate público, como elementos que dificultavam uma melhor mobilidade na capital catarinense. $\mathrm{O}$ debate sobre a mobilidade na capital catarinense avançou mostrando a necessidade de abordar elementos que iam além do transporte de pessoas e mercadorias, embora não se tenha ainda resolvido o problema de mobilidade em Florianópolis.

Esta diferenciação nos permite apontar que, por um lado, pode haver mobilidade sem transporte, e pode outro lado podem existir meios de transporte sem que haja mobilidade. Explico: quando a população tem suas necessidades supridas nas proximidades de sua casa; quando a cidade possui certa densidade (construtiva, de pessoas, mas também de diferenças de usos do solo), a mobilidade pode ser feita a pé (pedestrianismo) e os meios de transportes, motorizados ou não, são menos necessários para $o$ deslocamento. Da mesma forma, os meios de transporte podem ser tão caros em determinadas situações, que muitas pessoas não podem acessá-los, negando-se assim a mobilidade a uma parte da população.

\section{Mobilidade, cidade-direito e cidade-mercado}

A reflexão sobre cidade-direito e cidade-mercado é apresentada por Santos Junior (2007) quando ele discute questão 
PEREIRA, E.M. Cidade, urbanismo e mobilidade urbana.

da participação no planejamento urbano; essa discussão mostra-se igualmente importante quando se discute mobilidade urbana. Analisando o planejamento e a gestão das cidades brasileiras, Santos (2007) aponta para uma disputa de dois paradigmas de política urbana: a cidade-mercado e a cidade-direito. No primeiro, a participação política se daria a partir do "reconhecimento dos agentes como clientes-consumidores, portadores de interesses privados, impedindo a construção de uma esfera pública que represente o interesse coletivo" (p.306).

Diluem-se as ideias de totalidade e de cidadania, que perde sua conexão com a ideia de universalidade; divide o espaço político entre hipercidadãos e subcidadãos. Por sua vez, o paradigma cidade-direito está, segundo o autor, em construção, "tanto em relação ao aspecto teórico quanto em relação ao da práxis sócio-política" (p. 307). Ele "afirma o papel central do poder público no planejamento urbano e o seu compromisso com o enfrentamento dos mecanismos de produção de desigualdades e exclusão decorrentes da vigência da dinâmica do mercado no uso e ocupação do solo urbano e do controle do poder político pelos históricos interesses patrimonialistas" (p. 307).

Quando se encara a mobilidade apenas como um serviço urbano, o transporte é considerado um produto (ou uma mercadoria) e o habitante é considerado como um clienteconsumidor. Neste contexto, a discussão da tarifa torna-se central. Por outro lado, quando encarada como um direito, a mobilidade é colocada no patamar da saúde ou da educação públicas: na universidade pública brasileira, por exemplo, os custos são todos subsidiados com verbas públicas. Por quê? Porque a educação superior no Brasil é vista como direito fundamental; ela não é gratuita, mas financiada pelo conjunto da sociedade brasileira. Hegemonicamente, os governos municipais, responsáveis constitucionalmente pelo transporte público, tem abordado a mobilidade urbana como um serviço que deve ser pago principalmente pelos usuários do transporte público. Portanto, a 
PEREIRA, E.M. Cidade, urbanismo e mobilidade urbana.

visão que predomina no trato com o transporte urbano é o da cidade-mercado.

A importância da mobilidade vai além de um direito em si; ela é um direito que dá acesso a outros direitos, na medida em que ela possibilita ao cidadão ir ao trabalho, à escola, de acessar os equipamentos de saúde. Mas, o contrário também é verdadeiro: sem mobilidade, há um cerceamento do acesso aos direitos. Por exemplo, aquele cidadão que está procurando emprego e não tem dinheiro para pagar os meios de transporte, ele está sendo impedido do direito ao trabalho.

\section{$\mathbf{O}$ direito à cidade}

Além de ser um direito em si e dar acesso a outros direitos, a mobilidade urbana tem outro atributo fundamental: o de propiciar direito à cidade. Sobre o conceito de Direito à Cidade é necessário recorrer ao seu autor: durante a década de 1960, Henri Lefebvre, tendo até então trabalhado principalmente nas áreas sociológicas e filosóficas, concentrou a sua atenção nas questões geográficas e urbanas. Em 1968, este intelectual publicou um dos seus trabalhos mais importantes, a saber, $\mathrm{O}$ Direito à Cidade.

Nesta obra, ele propõe uma concepção alternativa do fazer e do viver a cidade, procurando restituir ao cidadão um poder de ação sobre o meio urbano e assim devolver-lhe uma capacidade de atuar sobre o seu ambiente. Aliás, a reflexão conduzida revela-se muito ampla e claramente ambiciosa: o direito à cidade se manifesta como forma superior dos direitos: direito à liberdade, à individualização na socialização, ao habitat e ao habitar. Uma capacidade plena de mobilidade no território da cidade, permitiria ao cidadão vivê-la em todas as suas dimensões. Mas Lefebvre adverte: "O direito à cidade não pode ser concebido como um simples direito de visita ou de retorno às cidades tradicionais. Só pode ser formulado como direito à vida urbana, transformada, renovada." (1968, p.116-7). 
PEREIRA, E.M. Cidade, urbanismo e mobilidade urbana.

Desde o século XIX, a questão da moradia constitui-se num verdadeiro desafio. Ao longo do tempo vários pensadores debruçaram-se sobre esta problemática. Evidentemente, houve médicos que se confrontaram com as condições de vida deploráveis dos seus doentes, e mais amplamente os intelectuais, preocupados com o destino dos mais pobres e com o estado de saúde no centro das cidades. O tema torna-se mesmo muito politizado.

O movimento marxista, que é, aliás, muito urbano em suas preocupações primordiais, encontrou notadamente aqui um terreno fértil para sua reflexão. Friedrich Engels (2008) pôde por exemplo descrever o destino das populações operárias vivendo na miséria e na insalubridade, antes de tratar a problemática da moradia de uma forma mais teórica. Com o tempo, porém, é mais amplamente todo o espectro político, os múltiplos atores públicos ou mesmo os industriais que tiveram que propor respostas, em particular soluções em termos de financiamento, para conter esse desastre.

Após muitas décadas, dado que na França foi necessário chegar aos anos de 1960, a questão da moradia tinha ficado menos problemática. E, embora a chegada massiva na métropole de populações francesas nascidas na Argélia provocasse algumas dificuldades, esta questão da moradia tinha sido ofuscada em benefício de outras prioridades. Ainda permaneciam, próximas a Paris, as favelas de Nanterre ou de Noisy-le-Grand, cujo desaparecimento aconteceria somente em meados da década de 1970. Mas no geral, a problemática da moradia tinha sido tratada com eficiência. $\mathrm{O}$ sistema produtivo tinha conseguido oferecer os meios técnicos que permitiram atender as várias carências de moradia. $\mathrm{E}$ os poderes públicos tinham se organizado e se estruturado para cumprir, o melhor possível, esta função.

E quando finalmente foi conseguido resolver o problema de falta de moradia e de condições sanitárias, Henri Lefebvre demonstra os limites da reflexão centrada, antes de tudo, na questão da moradia. O sociólogo e geógrafo francês vem neste momento sublinhar a questão do habitar. E, de certo modo, ele 
PEREIRA, E.M. Cidade, urbanismo e mobilidade urbana.

tende paradoxalmente se aproximar de alguns pontos da argumentação desenvolvida por Martin Heidegger, que aliás ele menciona várias vezes. A produção - extremamente materialista da moradia, não saberia satisfazer todas as necessidades antropológicas. O problema contemporâneo - explica o filósofo alemão - não é uma crise da moradia. É mais uma crise do habitar, do não saber mais habitar, e do não saber mais construir para o habitar. E, finalmente, é uma crise do ser (HEIDEGGER, 1973). Pois, segundo a fenomenologia heideggeriana, construção territorial e constituição ontológica são intimamente ligadas (HOYAUX, 2002).

Em Henri Lefebvre, a reflexão sobre o habitar toma uma forma mais social, e de certo modo mais política. Martin Heidegger, na sua demonstração, não integrava diretamente a questão do Outro. O ser estava à procura de um lar, pois está antes de tudo numa confrontação com o espaço. Para o pensador francês, "habitar" era participar de uma vida social, de uma comunidade, aldeia ou cidade. A vida urbana detinha, ente outras, essa qualidade, esse atributo. "Ela deixava habitar, permitia que os citadinos-cidadãos habitassem" (LEFEBVRE, 1968, p. 18).

Por trás da expressão de certa nostalgia, o autor define um habitar que não saberia existir sem sociabilidade, até mesmo sem urbanidade. Assim, o direito à cidade constitui, entre outras, uma tentativa de reaver a histórica relação entre o urbano e o citadino (entre urbs e civitas). Esta tem sido prejudicada por uma geração de ações urbanísticas de forma essencialmente quantitativa, avaliadas em função do número de moradias disponibilizadas, e através das quais parece monumentalizado a moradia, isto em detrimento de lugares e construcções mais comunitários, ou até mesmo públicos (PINSON, 1997).

Para Lefebvre, muitos dos problemas do urbanismo do século XX têm relação com o desconhecimento, por parte daqueles que intervinham na cidade, da essência da cidade e do urbano. 
PEREIRA, E.M. Cidade, urbanismo e mobilidade urbana.

\section{A mobilidade e sua relação com a cidade}

Assim como no urbanismo dos "homens de boa vontade" (LEFEBVRE, 1991), um dos grandes erros das políticas públicas setoriais ligadas à mobilidade está em não compreendê-las na sua relação com a cidade e sua complexidade. Ao contrário, há muito tempo vem se tentando simplificar o entendimento de cidade e por consequência, as soluções para os problemas urbanos são simplistas e ineficazes. Nesse aspecto, o urbanismo no século XX fez um desserviço à compreensão do que é cidade, por compará-la, ora com uma fábrica, ora com um organismo vivo ou com outra metáfora simplificadora: cidade não é nada disso; por mais que as metáforas tentem explicá-la, elas nunca chegarão próximas da complexidade do funcionamento, dos processos, das estruturas da cidade. Portanto, compreender o planejamento urbano sem compreender a geografia urbana é um grande erro. Da mesma forma, propor soluções para os problemas de mobilidade sem compreender a cidade não alcança o cerne da questão.

"O Urbanismo está na moda. As questões e reflexões urbanísticas saem dos círculos dos técnicos, dos especialistas, dos intelectuais que pretendem estar na vanguarda dos fatos. Passam para o domínio público através de artigos de jornais e livros ao alcance e ambição diferentes".

“ (...) E no entanto, as questões relativas à cidade e à realidade urbana não são plenamente conhecidas e reconhecidas; ainda não assumiram politicamente a importância e o significado que têm no pensamento e na prática" (LEFEBVRE, 1991, p.1).

Para compreendermos a cidade que chegou ao século XXI é preciso voltar na história: antes da industrialização as cidades tinham outra forma e outro conteúdo; a industrialização tomou a cidade de assalto. As imagens de Londres e de outras cidades da Inglaterra logo após a Revolução industrial eram imagens do caos urbano; isso em função do êxodo rural; a cidade chamava a 
PEREIRA, E.M. Cidade, urbanismo e mobilidade urbana.

população dos campos; a densidade ficou gigantesca. A Indústria trouxe para as cidades problemas que ela nunca teve. Londres passa de 400 mil para 4 milhões de habitantes em poucas décadas.

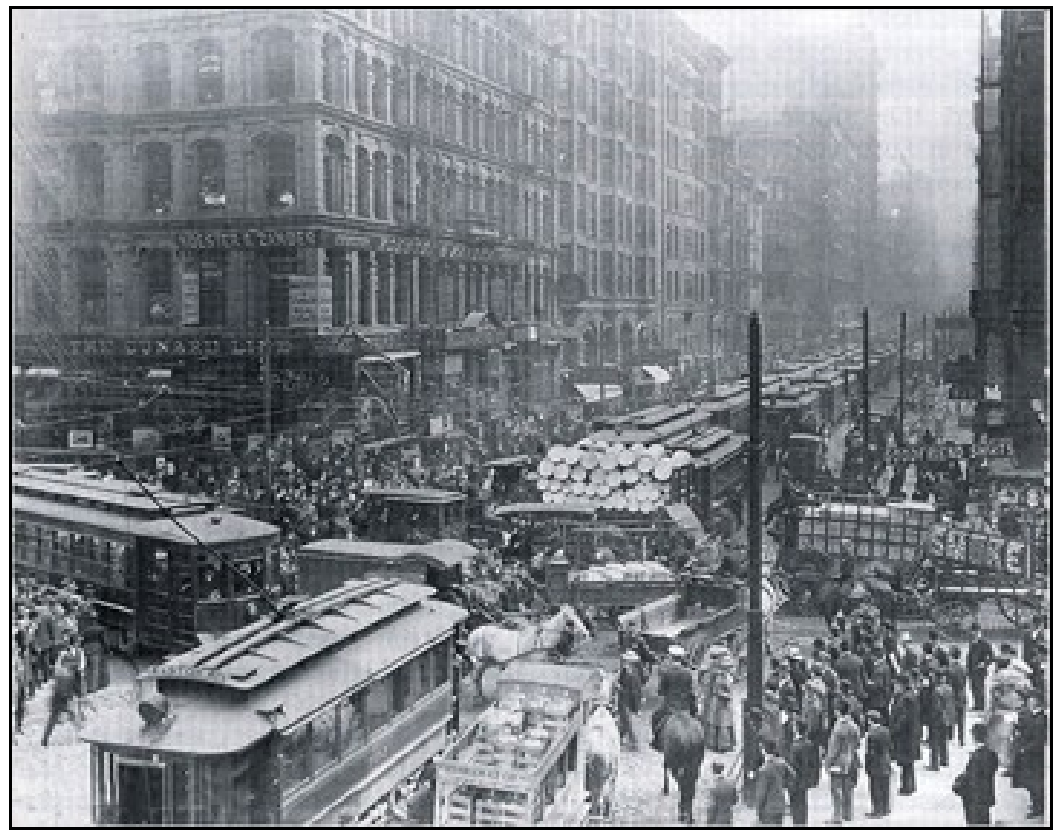

Figura 1: A cidade Industrial

Fonte : http://www.portalsaofrancisco.com.br/alfa/revolucao-industrial/ consequencias-da-industrializacao.php, acessado em 25/11/2014.

O processo de urbanização no Brasil, embora tardio, é igualmente acelerado. Entre 1940 e 1980, a proporção entre a população urbana e a população rural se inverte: a população urbana passa de 30\% a 70\%. Logo, a cidade que surge da revolução industrial apresenta problemas que antes não apresentava. Esses problemas exigem a invenção de uma área do conhecimento que antes também não existia: o urbanismo. A própria palavra urbanismo é inventada em 1870 por Idelfonso Cerda. 
PEREIRA, E.M. Cidade, urbanismo e mobilidade urbana.

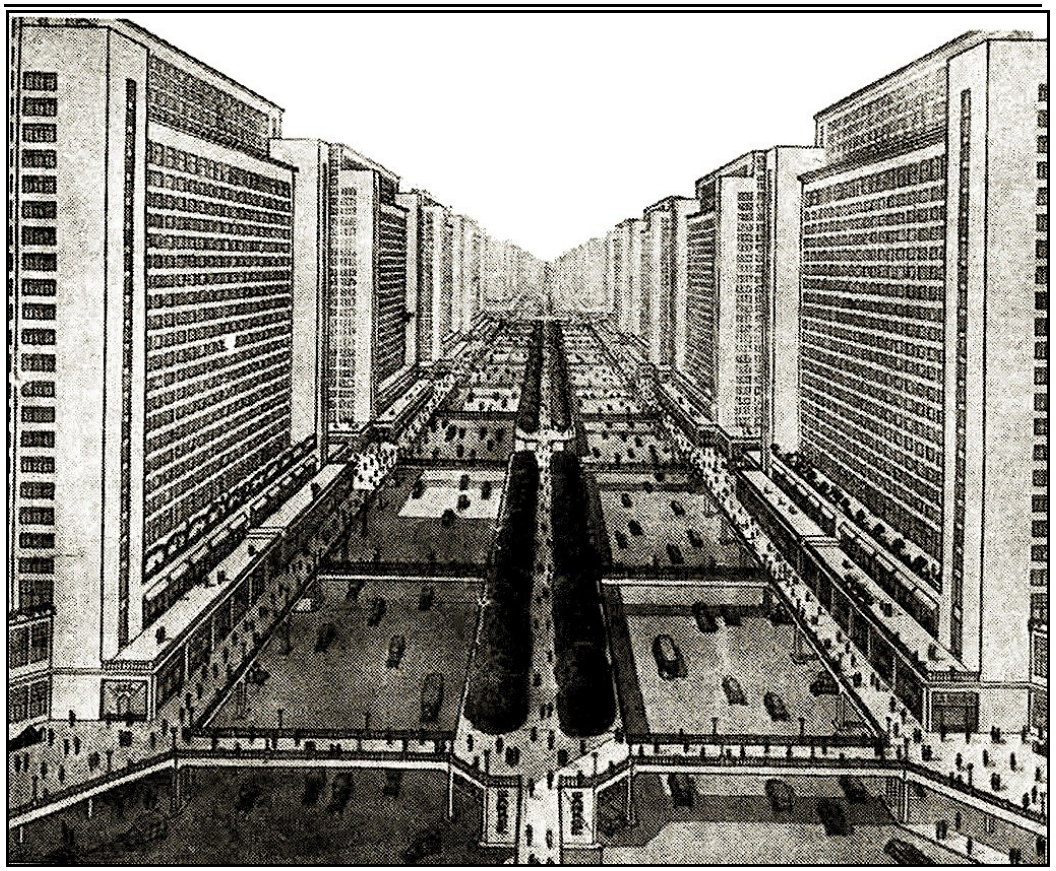

Figura 2: Ville Radieuse, de Le Corbusier de 1930

Fonte: http://thecharnelhouse.org/2010/09/17/exact-air/. Acessado em $25 / 11 / 2014$

O campo do conhecimento que surge da necessidade de dar respostas aos problemas que antes as cidades não apresentavam, vai propor uma organização que lhes simplifica a forma e suas funções. Essa simplificação leva a respostas insuficientes aos problemas urbanos. Era um urbanismo funcional e que incentivava a circulação. "Circulai, Circulai, Circulai", proclamava Le Corbusier, o grande ideário do urbanismo dito funcionalista ou modernista que foi hegemônico por todo o século XX. As soluções para a mobilidade eram buscadas a partir do sistema viário, que deveria funcionar como um sistema de grandes artérias, seguindo a metáfora da cidade como um organismo vivo. 
PEREIRA, E.M. Cidade, urbanismo e mobilidade urbana.

No entanto, no final do século $\mathrm{XX}$, as cidades e o planejamento funcionalista baseado no automóvel entraram em colapso. As primeiras críticas foram feitas na década de 1960 pela jornalista nova-iorquina Jane Jacobs (2000); em 1968, Henry Lefebvre critica severamente toda uma geração de técnicos em urbanismo que resolveram o problema do défict habitacional francês do pós-guerra desvinculando o Habitar do Habitat e simplificando ao extremo a compreensão da cidade.

"declarar que a cidade se define como rede de circulação e de consumo, como centro de informação e de decisões é uma ideologia, que procede de uma redução-extrapolação particularmente arbitrária e perigosa, se oferece como verdade total e dogma, utilizando meios terroristas. Leva ao urbanismo dos canos, da limpeza pública, dos medidores, que se pretende impor em nome da ciência e do rigor científico. Ou coisa pior ainda" (LEFEBVRE, 1991, p.43).

A incompreensão do que é a cidade concorreu em grande parte para o colapso do modelo de urbanismo do século XX. A palavra cidade denomina todas as realidades urbanas, mas não dá conta de todas as cidades. Lefebvre coloca que a cidade é diversa e que não é possível compreendê-la apenas a partir daquilo que ele chama de ordem próxima, nem apenas daquilo que acontece globalmente:

"A cidade sempre teve relações com a sociedade no seu conjunto, com sua composição e seu funcionamento, com seus constituintes, com sua história. Portanto, ela muda quando muda a sociedade em seu conjunto. Entretanto, as transformações da cidade não são os resultados passivos da globalidade social, de suas modificações. A cidade depende também e menos essencialmente das relações de imediatice, das relações diretas entre as pessoas e grupos que compõem a sociedade" (LEFEBVRE, 1991, p.46).

Essa dialética do local e do global é que vai explicar as diversas materializações das cidades. Vamos exemplicar através da 
PEREIRA, E.M. Cidade, urbanismo e mobilidade urbana.

análise do engarrafamento no trânsito que acontece cotidianamente em Florianópolis: aquele que acontece nos acessos das pontes Colombo Sales e Pedro Ivo. Do ponto de vista local, o congestionamento pode ser explicado pela existência de apenas uma ligação rodoviária entre a ilha de Santa Catarina e o continente próximo. Essa parece ser uma explicação plausível e aceita. Mas se considerarmos que na última década existiu uma política federal que incentivou a compra de automóveis através da renúncia fiscal do IPI por parte do governo, podemos considerar que boa parte do congestionamento pode ser também explicada pelo excessivo número de automóveis circulantes nas cidades brasileiras.

Mesmo Curitiba, que possui um dos sistemas de transporte coletivo mais desenvolvido do país, apresenta um índice na ordem de 1,8 habitantes por carro, o maior entre as capitais estaduais do país. Assim, o congestionamento poderia ser explicado pela soma das condições locais com a política federal de incentivo à compra de automóveis. Mas, podemos acrescentar ainda que essa política de IPI reduzido se propõe a combater uma crise econômica mundial, que atinge grande parte dos países. Então a cidade de Florianópolis sofre não só por questões locais, mas igualmente por fatores de ordem distantes: nacional e mundial.

Além disto, Lefebvre vai acrescentar que a análise dos fenômenos urbanos exige o emprego de todos os instrumentos metodológicos: "forma, função, estrutura, dimensões de texto/contexto, campo/conjunto, escrita e leitura, sistema, significante e significado, linguagem e metalinguagem, instituições etc." (LEFEBVRE, 1991, p 58).

Como exemplo da análise desses fenômenos, vamos explorar a questão da relação entre a forma das cidades e a mobilidade. O gráfico 1 apresenta uma relação do consumo per capita de combustíveis e as densidades de algumas cidades no mundo. As cidades americanas apresentam um alto consumo de combustível em função da baixa densidade. As europeias apresentam maior densidade que as americanas e um menor consumo de combustível para transporte per capita $\mathrm{E}$ as cidades 
PEREIRA, E.M. Cidade, urbanismo e mobilidade urbana.

como Moscou e Hong Kong apresentam densidade muito alta e o consumo de energia em transporte, per capita, muito baixo.

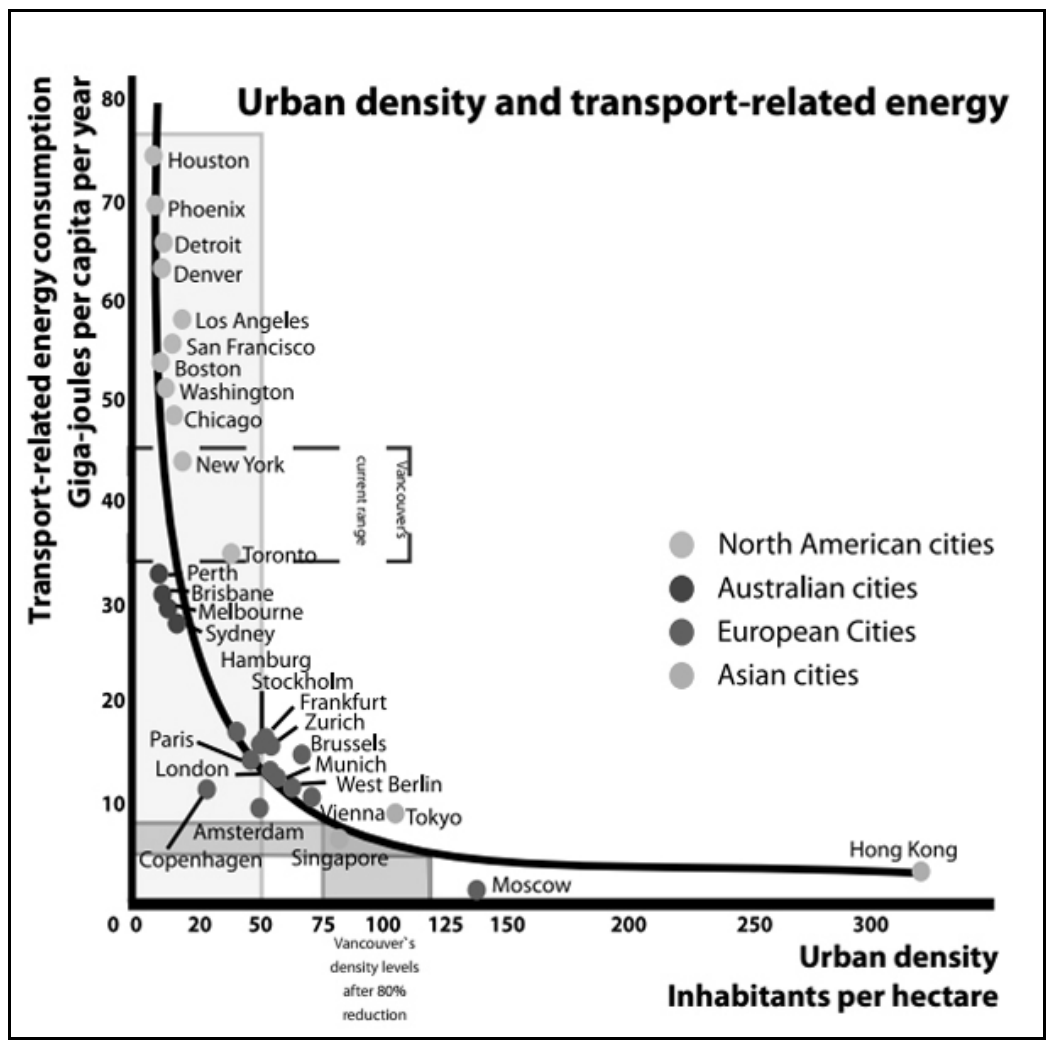

Gráfico 1: Densidade urbana versus consumo de energia em transporte

Fonte: http://blog.environmentalresearchweb.org/2011/07/26/urbandensity-and-fuel-consump-1/, acessado em 25/11/2014.

Se analisarmos, por exemplo, Houston, veremos uma cidade com baixa densidade e um alto consumo de energia para transporte per capita; estudando um pouco a morfologia dessa cidade, 
PEREIRA, E.M. Cidade, urbanismo e mobilidade urbana.

encontraremos um centro verticalizado, mas com baixa densidade habitacional, e um subúrbio distante onde mora grande parte da população. Entre esses dois espaços, estão localizadas várias autoestradas destinadas ao deslocamento dos habitantes da cidade, muitas delas com congestionamentos diários. Trata-se de um movimento caracterizado como pendular entre o centro e a periferia, que está relacionado diretamente a forma da cidade. A figura 3 ilustra tal realidade.

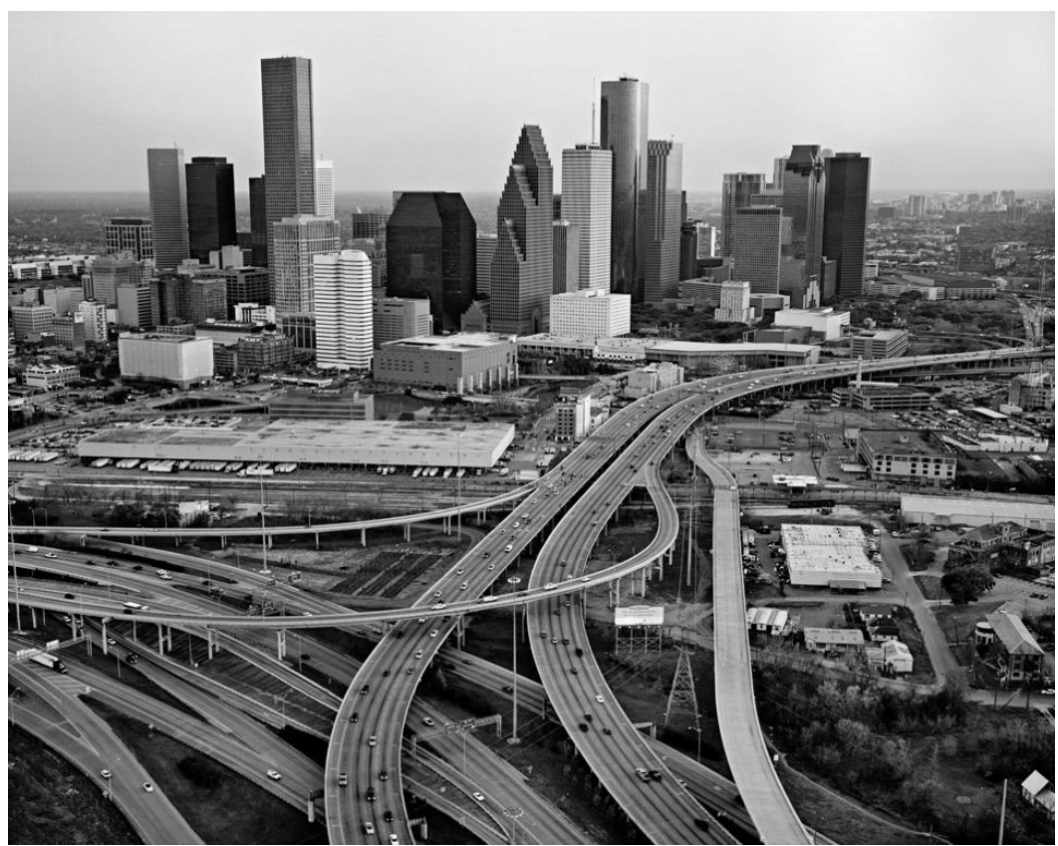

Figura 3: Houlston, EUA.

Fonte: http://blog.comshalom.org/carmadelio/tag/homossexualidade, acessada em 25/11/2014.

No começo de julho deste ano estive em Xanxerê/SC, cidade de 20 mil habitantes. Apresentei essas informações numa palestra e coincidentemente a prefeitura local estava discutindo a 
PEREIRA, E.M. Cidade, urbanismo e mobilidade urbana.

possibilidade de aumentar o perímetro urbano da município. Apresentei um rápido estudo e mostrei que, com o mesmo perímetro urbano que o município possui hoje com uma densidade razoável, eles poderiam chegar a 220 mil habitantes. A cidade abrigaria uma população cinco vezes maior que aquela que possui hoje sem aumentar as distâncias urbanas hoje existentes. Mantendo a mesma densidade atual, haveria a necessidade de aumentar em muito seu perímetro urbano para alcançar tal população. $\mathrm{Na}$ primeira hipótese seria, sem dúvida, uma cidade com uma morfologia que demandaria deslocamentos diários menores, com menos dispêndio de energia para transporte per capita.

Assim vemos que a compreensão dos problemas da cidade passa por uma análise dos fenômenos urbanos de forma complexa, pois a cidade é complexa; se desvincularmos as questões de mobilidade das questões urbanas, nós não vamos conseguir responder aos problemas, nem encontrar as soluções.

O pensamento crítico sobre o urbanismo levou a repensar os fundamentos do urbanismo hegemônico do século XX que era (é) baseado, sobretudo na circulação de automóveis e na necessidade de construção de grandes estruturas viárias para dar vazão a esta circulação.

A partir da crítica a esse modelo rodoviarista, algumas cidades no mundo estão inclusive destruindo estruturas viárias, como autoestradas e viadutos, e refazendo o espaço urbano a partir da ideia da cidade como lugar de permanência e do convívio humano. Foi o caso de Seul (Coreia do Sul), por exemplo, que se propôs a voltar atrás: uma autoestrada urbana foi destruída restaurando um curso d'água que havia sido coberto. É um exemplo que mostra um movimento tentando repensar o urbanismo desenvolvido durante o século XX. 
PEREIRA, E.M. Cidade, urbanismo e mobilidade urbana.

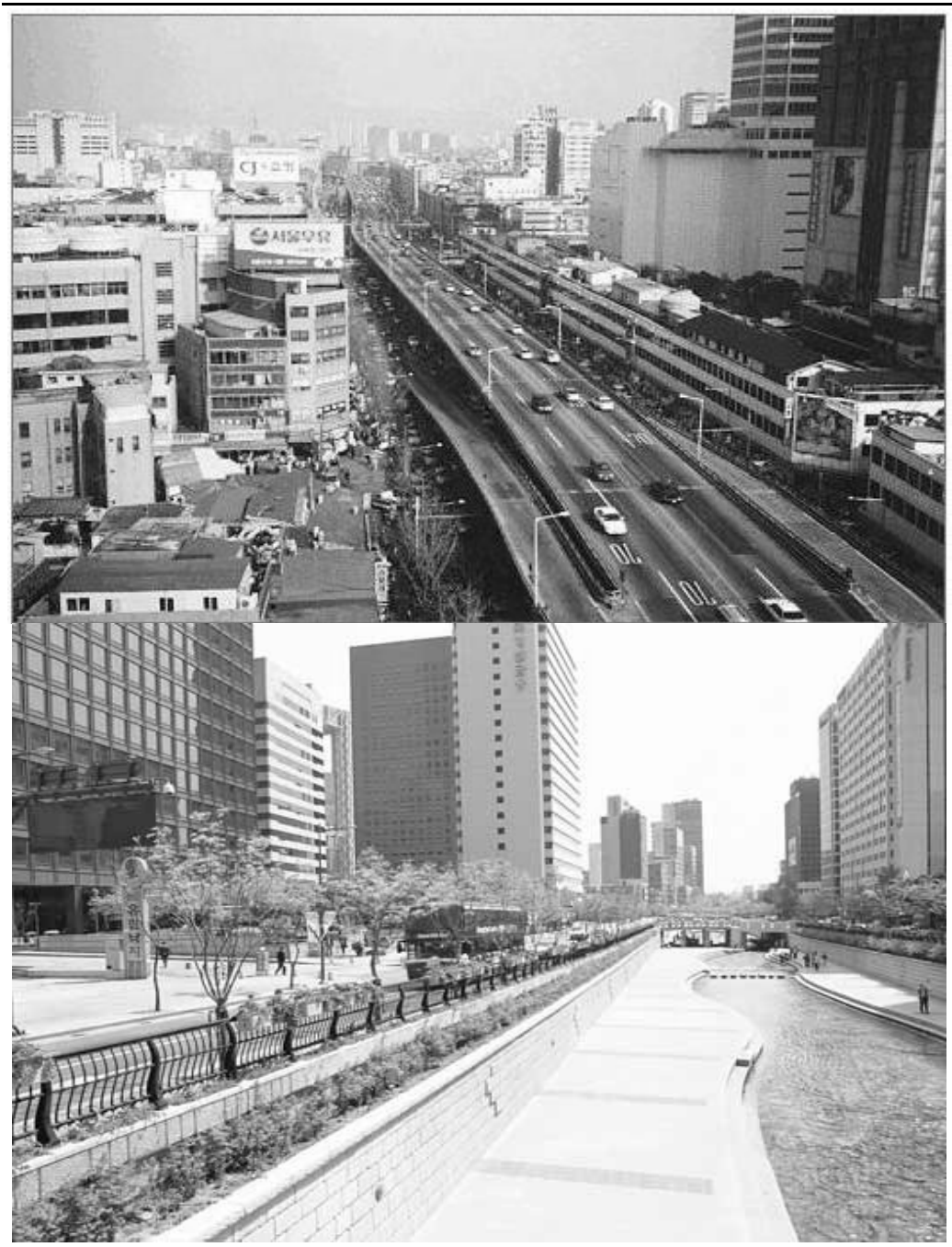

Figura 3: Dois momentos da autoestrada destruída em Seul: urbanismo repensado

Fonte: http://portalarquitetonico.com.br/uma-impressionante-renovacaourbana-em-seul/ 
PEREIRA, E.M. Cidade, urbanismo e mobilidade urbana.

É preciso então repensar a mobilidade articulada a reflexão sobre a cidade, sua forma, suas funções, sua estrutura e seus processos.

\section{Considerações conclusivas}

A partir desta forma de pensar, a mobilidade urbana apresenta-se como uma variável dependente; ela é resultante do modelo de cidade implantado; mais ou menos pensado de acordo com os planos urbanísticos, mas totalmente dependente da forma de urbanização. A seguir apresentamos algumas reflexões conclusivas:

Primeiramente é preciso considerar a mobilidade como uma realidade constitutiva da sociedade contemporânea. É preciso mais do que nunca, considerar as condições urbanas da mobilidade. Segundo Chalas (2007), "se existe uma dimensão a se levar realmente em conta para se tentar compreender o que se tornaram as cidades no mundo, é a dimensão da mobilidade (...). Não somente os habitantes se deslocam mais frequentemente, como eles vão mais longe" (p.35). E ele acrescenta: o que confere à mobilidade sua plena significação e seu caráter radicalmente inovador, são suas implicações sociais e espaciais sem precedente histórico segundo quatro perspectivas essenciais:

1.1. A mobilidade atual em nossas cidades surge de uma lógica de ruptura ou de mutação civilizacional: na cidade de antigamente, a mobilidade era considerada apenas como um elemento complementar do sedentarismo; hoje ela é fundadora de redes de pertencimento, de modos de apropriação dos territórios, conferindo à fixidez um papel subalterno: “o marginal urbano, o excluído, é, em nossos dias, o ser bloqueado, o ser incapaz de se movimentar a grandes distâncias e regularmente"'(p.36).

1.2. A segunda perspectiva é a falsa ideia de que a cidade acabará com a necessidade de mobilidade; "a cidade poderá, deverá até, se fazer contra o automóvel 
PEREIRA, E.M. Cidade, urbanismo e mobilidade urbana.

invasor (...) mas ela, a cidade, não se fará contra a mobilidade em si" (37).

1.3. A terceira perspectiva é a que permite interpretar que existe uma interpenetração entre cidade e mobilidade: "na figura da cidade-móvel, deslocamento e espacialidade se recortam até se confundirem, chegando a constituir uma única e mesma realidade" (p.38).

1.4. Por fim, é preciso compreender que a mobilidade não é apenas um fato técnico, ela é igualmente um fato cultural.

Em Segundo, é preciso apreender a dimensão urbana da mobilidade. O corolário sesse aspecto é que para combater os problemas da falta de mobilidade em nossas cidades é preciso ir além das questões puramente técnicas; é preciso compreender as práticas sociais que acontecem na cidade; é preciso considerar a forma como se estrutura a cidade; é preciso tratar das políticas públicas de forma intersetorial, buscando-se uma transversalidade da análise. Além disto, o atual estágio de desenvolvimento de consciência da sociedade, exige que as soluções de mobilidade contemplem aspectos relacionados ao respeito ambiental e à acessibilidade universal.

Por fim, é preciso mais uma vez recorrer a Lefebvre; assim como o urbanismo não pode ser conduzido sem a compreensão do que é a cidade, os problemas de mobilidade não serão resolvidos sem que tenhamos o domínio do fenômeno urbano. Além disto, assim como o autor francês fala em suas conclusões, é preciso resgatar, na cidade, o homem na sua relação social: a realização da sociedade urbana exige um planejamento orientado para as necessidades sociais, as necessidades da sociedade urbana. 
PEREIRA, E.M. Cidade, urbanismo e mobilidade urbana.

\section{Referências bibliográficas}

CHALAS, Yves. Cidades contemporâneas. IN: PEREIRA, Elson M. e FERRARI, Maristela (org). Dossiê Abordagens Geográficas. Revista Grifos, n, 22 e 23, junho/dezembro. Chapecó, 2007, p.3365.

ENGELS, F. A Situação da Classe Trabalhadora na Inglaterra. São Paulo: Boitempo, 2008.

FELDMAN, Sarah e FERNANDES, Ana (org). O Urbano e o Regional no Brasil Contemporâneo: mutações, tensões, desafios. Salvador: EDUFBA, 2007, p. 293-314.

HEIDEGGER M. Batir, habiter, penser. Essais et conférences. Paris : Gallimard, trad. André Préau, 1973, p. 170-193.

HOYAUX, A. F. Entre construction territoriale et constitution ontologique de l'habitant: Introduction épistémologique aux apports de la phénoménologie au concept d'habiter. Cybergeo : European Journal of Geography, Epistémologie, Histoire de la Géographie, Didactique, artigo 216, 2002.

JACOBS, Jane. Morte e vida de grandes cidades. São Paulo: Martins Fontes, 2000.

LEFEBVRE, Henry. Le Droit à la ville. Paris: Anthropos.1968.

. O Direito à Cidade. São Paulo: Moraes, 1991.

PINSON, D. La monumentalisation du logement: l'architecture des ZUP comme culture. Les Annales de la recherche architecturale. 1997, p. 51-62. 
PEREIRA, E.M. Cidade, urbanismo e mobilidade urbana.

SANTOS JUNIOR, Orlando. Cidade, Cidadania e Planejamento Urbano: desafios na perspectiva da Reforma Urbana. IN:

\section{Internet}

http:/www.portalsaofrancisco.com.br/alfa/revolucaoindustrial/con sequencias-da-industrializacao.php, acessado em 25/11/2014. http://thecharnelhouse.org/2010/09/17/exact-air/,acessado em $25 / 11 / 2014$

http://blog.environmentalresearchweb.org/2011/07/26/urbandensity-and-fuel-consump-1/ acessado em 25/11/2014

http://blog.comshalom.org/carmadelio/tag/homossexualidade acessado em 25/11/2014.

http://portalarquitetonico.com.br/uma-impressionante-renovacaourbana-em-seul/ a acessado em 25/11/2014.

Recebido em

Aceito em 